\title{
Estimation of inbreeding using pedigree, 50k SNP chip genotypes and full sequence data in three cattle breeds
}

\author{
Qianqian Zhang ${ }^{1,2^{*}}$, Mario PL Calus², Bernt Guldbrandtsen ${ }^{1}$, Mogens S Lund ${ }^{1}$ and Goutam Sahana ${ }^{\text {* }}$
}

\begin{abstract}
Background: Levels of inbreeding in cattle populations have increased in the past due to the use of a limited number of bulls for artificial insemination. High levels of inbreeding lead to reduced genetic diversity and inbreeding depression. Various estimators based on different sources, e.g., pedigree or genomic data, have been used to estimate inbreeding coefficients in cattle populations. However, the comparative advantage of using full sequence data to assess inbreeding is unknown. We used pedigree and genomic data at different densities from 50k to full sequence variants to compare how different methods performed for the estimation of inbreeding levels in three different cattle breeds.

Results: Five different estimates for inbreeding were calculated and compared in this study: pedigree based inbreeding coefficient $\left(\mathrm{F}_{\mathrm{PED}}\right)$; run of homozygosity $(\mathrm{ROH})$-based inbreeding coefficients $\left(\mathrm{F}_{\mathrm{ROH}}\right)$; genomic relationship matrix (GRM)-based inbreeding coefficients $\left(F_{G R M}\right)$; inbreeding coefficients based on excess of homozygosity $\left(F_{\text {HOM }}\right)$ and correlation of uniting gametes ( $\mathrm{F}_{\mathrm{UN}} \mathrm{I}$ ). Estimates using $\mathrm{ROH}$ provided the direct estimated levels of autozygosity in the current populations and are free effects of allele frequencies and incomplete pedigrees which may increase in inaccuracy in estimation of inbreeding. The highest correlations were observed between $\mathrm{F}_{\mathrm{ROH}}$ estimated from the full sequence variants and the $\mathrm{F}_{\mathrm{ROH}}$ estimated from 50k SNP (single nucleotide polymorphism) genotypes. The estimator based on the correlation between uniting gametes ( $\left.F_{U N}\right)$ using full genome sequences was also strongly correlated with $\mathrm{F}_{\mathrm{ROH}}$ detected from sequence data.

Conclusions: Estimates based on $\mathrm{ROH}$ directly reflected levels of homozygosity and were not influenced by allele frequencies, unlike the three other estimates evaluated ( $F_{G R M}, F_{H O M}$ and $\left.F_{U N N}\right)$, which depended on estimated allele frequencies. $F_{P E D}$ suffered from limited pedigree depth. Marker density affects $\mathrm{ROH}$ estimation. Detecting ROH based on 50k chip data was observed to give estimates similar to $\mathrm{ROH}$ from sequence data. In the absence of full sequence data $\mathrm{ROH}$ based on 50k can be used to access homozygosity levels in individuals. However, genotypes denser than 50k are required to accurately detect short $\mathrm{ROH}$ that are most likely identical by descent (IBD).
\end{abstract}

Keywords: Inbreeding, Cattle, Whole-genome sequence, Runs of homozygosity

\section{Background}

The definition of inbreeding coefficient $(F)$ is the probability that two alleles in an individual are identical by descent (IBD) relative to a base population where all alleles are assumed unrelated [1]. Rates of inbreeding have increased as intensive selection was applied to the populations [2-7]. Increased levels of inbreeding result in increased probability that animals are homozygous for

\footnotetext{
*Correspondence: Qianqian.zhang@mbg.au.dk; Goutam.sahana@mbg.au.dk ${ }^{1}$ Department of Molecular Biology and Genetics, Center for Quantitative Genetics and Genomics, Aarhus University, Tjele DK-8830, Denmark Full list of author information is available at the end of the article
}

deleterious alleles $[2,8,9]$. Thus, inbred animals suffer from inbreeding depression with reduced fitness, and highly inbred animals may have considerably reduced lifespans $[2,6,10-13]$. Information on inbreeding is critical in the design of breeding program to control the increase in inbreeding levels and thereby controlling inbreeding depression in the progeny. Pedigree information has been used to calculate the estimated inbreeding coefficient as the expected probability that two alleles at a locus are IBD [14-16]. For example, Meuwissen and Luo proposed a method to estimate inbreeding coefficients based on pedigree data of large populations [17].

\section{Biomed Central}


However, incomplete pedigrees result in erroneous estimates and an underestimation of levels of inbreeding [18]. VanRaden proposed a method to take into account unknown ancestors when estimating inbreeding coefficients, increasing the accuracy of inbreeding level estimates in incomplete pedigrees [19].

With the availability of Single Nucleotide Polymorphism (SNP) array genotyping technologies, long stretches of homozygous genotypes, known as runs of homozygosity $(\mathrm{ROH})$ can be identified. $\mathrm{ROH}$ are believed to reflect an estimate of autozygosity on genomic level and generally identify genomic regions which are IBD $[20,21]$. Theoretically, it is expected that $\mathrm{ROH}$ can be accurately estimated from the full sequence data, because these estimates do not suffer from sampling such as may be expected when subsets of loci, for instance 50k SNPs, are used [22-24]. The inbreeding coefficient can be calculated as the proportion of genome covered by $\mathrm{ROH}$ and has been shown to be more informative than the inbreeding coefficient estimated from pedigree data or other estimators because $\mathrm{ROH}$ strongly correlate with homozygous mutation load [25]. ROH have commonly been used to infer population history and to examine the effect of deleterious homozygotes caused by inbreeding in human populations [20, 26-29]. Long $\mathrm{ROH}$ reflect recent inbreeding, whereas short $\mathrm{ROH}$ reflect ancient inbreeding [26]. However, only a few studies have evaluated $\mathrm{ROH}$ in cattle populations. Ferenčaković et al. examined the effect of SNP density and genotyping errors when estimating autozygosity from high-throughput genomic data [24]. Estimates based on $\mathrm{ROH}$ also vary with different densities of genomic data. The minimum length of $\mathrm{ROH}$ that can be detected depends on SNP density [24, 30]. Recently, Purfield et al. detected $\mathrm{ROH}$ in a cattle population from SNP chip data to infer population history [31]. However, to estimate the "true" state of $\mathrm{ROH}$, whole-genome sequences should be used rather than SNP chip data, but, to date, there are only few studies doing this in cattle [32]. With the advent of next-generation sequencing technology, wholegenome sequences have become available to examine the fine-scale genetic architecture of the cattle genome. It is now possible to investigate and compare how well different commonly used estimators of inbreeding level correlate with $\mathrm{ROH}$ estimated using next-generation sequence (NGS) data.

In recent years, widespread availability of genotype data enabled computation of inbreeding from the diagonals of genomic relationship matrices, i.e., the "GRM" method $\left(\mathrm{F}_{\mathrm{GRM}}\right)$, as a by-product of genomic selection. Similarly, using the genotypes, the inbreeding coefficient can be computed based on excess of homozygosity following Wright (1948) ( $\left.\mathrm{F}_{\mathrm{HOM}}\right)$ [33] and based on correlation between uniting gametes following Wright (1922) $\left(\mathrm{F}_{\mathrm{UNI}}\right)$ [1]. The objective of the present study was to compare different estimators for inbreeding coefficients calculated from pedigree, 50k SNP chip genotypes and full sequence data with estimates based on $\mathrm{ROH}$, for three different dairy cattle breeds.

\section{Methods}

\section{SNP genotyping and sequencing}

A total of 89 bulls with a high genetic contribution to current Danish dairy cattle populations were selected for whole-genome resequencing. These included 32 Holstein (HOL), 27 Jersey (JER), and 30 Danish Red Cattle (RDC) bulls. RDC cattle are a composite breed with contributions from different red breeds, including Swedish Red, Finnish Ayrshire, and Brown Swiss [34]. Only bi-allelic variants SNPs with a phred-scaled quality score [35] higher than 100 were kept for analysis to ensure the quality of variants. Genotypes were extracted from whole-genome sequence (WGS) data using GATK [36] and a perl script. The sequence variants with read depth lower than 7 or higher than 30 were filtered out. In addition, 85 of the sequenced animals were genotyped with the Illumina 50k SNP assay (BovineSNP50 BeadChip version 1 or 2, Illumina, San Diego, CA). SNP genotyping and quality control were as described by Höglund et al. [37]. Among the whole genome sequenced animals, 4 animals were not genotyped with the 50k SNP chip. Their genotypes for the SNPs on the 50k chip were extracted from their whole-genome sequences. The quality of genotype calls from SNP chips is expected to be higher than that of whole-genome sequences; therefore, only sequence variants with a high quality score (phred score $>100$ ) were included. The corresponding corrections for reverse strand calls in the sequence data were converted to Illumina calls by correcting locus calling from reverse strands in Illumina calls to maintain consistency of allele encoding between Illumina calls and sequence data. The concordance between the SNP chip and sequence data was $~ 97 \%$.

\section{Estimation of inbreeding Using pedigree records ( $\left.F_{P E D}\right)$}

Inbreeding coefficients for the 89 bulls were estimated using pedigree records $\left(\mathrm{F}_{\mathrm{PED}}\right)$. The average pedigree depth was $\sim 8$ generations ranging from 3 to 13 . Average pedigree depth was 7, 8 and 9 for HOL, JER, and RDC, respectively. The method proposed by VanRaden [19] was used to compute inbreeding coefficients, which replaces unknown inbreeding coefficients by average inbreeding coefficients in the same generations. Inbreeding coefficients were calculated using the following formula [38]:

$$
A_{i i}=\sum_{j=1}^{i} L_{i j}^{2} D_{j j}
$$

where $A_{i i}$ is the $i^{\text {th }}$ diagonal element of the $\mathbf{A}$ matrix (pedigree relationship matrix), which is equal to the 
inbreeding coefficient of the $i^{\text {th }}$ animal plus 1 . $\mathrm{L}$ is a lower triangular matrix containing the fraction of the genes that animals derive from their ancestors, and D is a diagonal matrix containing the within family additive genetic variances of animals [17]. The computation for matrix elements $L_{i j}$ and $D_{i j}$ follows the rule of computation of the A matrix [17]. The detailed decomposition for computing $A_{i i}$ is explained by Meuwissen and Luo [17]. The analysis was conducted using Relax2 software [39].

\section{Using genotypes $\left(F_{R O H}, F_{G R M}, F_{H O M}, F_{U N I}\right)$}

Sequence data $\mathrm{ROH}$ were detected from sequence data using all bi-allelic variants according to the method of Bosse et al. [23]. This method was used to compute ROH for sequence data instead of PLINK because not all short $\mathrm{ROH}$ can be detected using PLINK for sequence data (the sliding window size in PLINK is fixed; therefore, $\mathrm{ROH}$ shorter than a certain length cannot be detected). The measure of homozygosity based on $\mathrm{ROH}\left(\mathrm{F}_{\mathrm{ROH}}\right)$ from genomic data is defined as the total length of genome covered by $\mathrm{ROH}$ divided by the overall length of genome covered by SNPs or sequences as follows [20]:

$$
\mathrm{F}_{\mathrm{ROH}}=\frac{\mathrm{L}_{\mathrm{ROH}}}{\mathrm{L}_{\mathrm{AUTO}}}
$$

where $\mathrm{L}_{\mathrm{ROH}}$ is the sum of $\mathrm{ROH}$ lengths and $\mathrm{L}_{\mathrm{AUTO}}$ is the total length of autosomes covered by reads. The inbreeding coefficient was calculated by extracting $\mathrm{ROH}$ from sequence data. Three $\mathrm{ROH}$ estimates based on lengths were calculated from sequence data. The $\mathrm{ROH}$ was calculated separately by summing the $\mathrm{ROH}$ in different length classes: 1) based on all $\mathrm{ROH}$; 2) $\mathrm{ROH}>1$ Mbp; 3) $\mathrm{ROH}>3$ Mbp.

In addition, three other estimates of inbreeding coefficients were calculated using sequence data $\left(\mathrm{F}_{\mathrm{GRM}}\right.$, $\mathrm{F}_{\mathrm{HOM}}, \mathrm{F}_{\mathrm{UNI}}$ ). The $\mathrm{F}_{\mathrm{GRM}}$ estimate was calculated following VanRaden (2008) [40] based on the variance of the additive genotypes. $\mathrm{F}_{\mathrm{GRM}}$ was derived from

$$
\mathrm{F}_{\mathrm{GRM}}=\frac{\left[x_{i}-E\left(x_{i}\right)\right]^{2}}{h_{i}}-1=\frac{\left(x_{i}-2 \hat{p}_{i}\right)^{2}}{h_{i}}-1
$$

where $p_{i}$ is the observed fraction of the first allele at locus $i, h_{i}=2 p_{i}\left(1-p_{i}\right)$ and $x_{i}$ is the number of copies of the reference allele (i.e., the allele whose homozygous genotype was coded as "0") for the $i^{\text {th }}$ SNP [41]. This was equivalent to estimating an individual's relationship to itself (diagonal of the SNP-derived GRM). The $\mathrm{F}_{\mathrm{HOM}}$ estimate was calculated based on the excess of homozygosity following Wright (1948) [33]:

$$
\begin{aligned}
\mathrm{F}_{\mathrm{HOM}} & =[\mathrm{O}(\# \text { hom })-\mathrm{E}(\# \text { hom })] /[1-\mathrm{E}(\# \text { hom })] \\
& =1-\frac{x_{i}\left(2-x_{i}\right)}{h_{i}}
\end{aligned}
$$

where $\mathrm{O}$ ( hom) and $\mathrm{E}$ (\# hom) are the observed and expected numbers of homozygous genotypes in the sample, respectively [41]. The $\mathrm{F}_{\mathrm{UNI}}$ estimate was calculated based on the correlation between uniting gametes following Wright (1922) [1]:

$$
\mathrm{F}_{\mathrm{UNI}}=\frac{x_{i}^{2}-\left(1+2 p_{i}\right) x_{i}+2 p_{i}^{2}}{h_{i}},
$$

where $h_{i}$ and $x_{i}$ are the same as for $\mathrm{F}_{\mathrm{GRM}}$ [41]. The calculations for these three estimates $\mathrm{F}_{\mathrm{GRM}}, \mathrm{F}_{\mathrm{HOM}}$ and $\mathrm{F}_{\mathrm{UNI}}$ were computed using the option $-i b c$ from GCTA software [41].

50k SNP chip ROH were detected from 50k SNP chip data using the software PLINK with adjusted parameters (-homozyg-density 1000, -homozyg-window-het 1, homozyg-kb 10, -homozyg-window-snp 20) [23, 42]. These settings for PLINK to detect $\mathrm{ROH}$ in SNP data were chosen to make the detected $\mathrm{ROH}$ in SNP chip data and sequence data as similar as possible to enable comparisons of results when using different types of data. Genomic estimates of the inbreeding coefficient based on all $\mathrm{ROH}$ $\left(\mathrm{F}_{\mathrm{ROH}}\right)$ were calculated using the same formula as was used for the sequence data. The other three types of estimates $\left(\mathrm{F}_{\mathrm{GRM}}, \mathrm{F}_{\mathrm{HOM}}, \mathrm{F}_{\mathrm{UNI}}\right)$ were also calculated for genotypes extracted from 50k SNP chip data using the same methods as for sequence data.

Pearson's correlation coefficients were calculated between estimates of inbreeding coefficients from each of pedigree records, 50k SNP genotypes, and whole-genome sequence variants. All correlations between different inbreeding coefficient estimators were tested within breed to determine whether they were significantly different from 0 using the $\mathrm{R}$ (http://www.r-project.org/) cor and cor.test functions.

\section{Impact of allele frequencies on estimators of inbreeding}

As some estimators explicitly use allele frequencies to compute inbreeding coefficients, it is important to investigate how varying allele frequencies affect estimated inbreeding coefficients. Here, we investigated how the three different estimators change across the whole range of allele frequencies. For each genotype $x_{i}$ (homozygous for the reference allele; heterozygous for the reference and non-reference allele; homozygous for the nonreference allele), the values can be written as a function of allele frequency $p_{i}$, as shown in Table 1. 
Table 1 Formula for calculating three estimators ( $F_{G R M}, F_{\mathrm{HOM}}$ and $F_{U N I}$ ) for each genotype (homozygous for reference allele; heterozygous for reference and non-reference allele; homozygous for non-reference allele)

\begin{tabular}{llll}
\hline & $\mathrm{F}_{\mathrm{GRM}}$ & $\mathrm{F}_{\mathrm{HOM}}$ & $\mathrm{F}_{\text {UNI }}$ \\
\hline$x_{i}=0$ & $\mathrm{~F}_{\mathrm{GRM}}=\frac{3 p_{i}-1}{1-p_{i}}$ & $\mathrm{~F}_{\mathrm{HOM}}=1$ & $\mathrm{~F}_{\mathrm{UNI}}=\frac{p_{i}}{1-p_{i}}$ \\
$x_{i}=1$ & $\mathrm{~F}_{\mathrm{GRM}}=\frac{6 p_{i}{ }^{2}-6 p_{i}+1}{2 p_{i}\left(1-p_{i}\right)}$ & $\mathrm{F}_{\mathrm{HOM}}=1-\frac{1}{2 p_{i}\left(1-p_{i}\right)}$ & $\mathrm{F}_{\mathrm{UNI}}=-1$ \\
$x_{i}=2$ & $\mathrm{~F}_{\mathrm{GRM}}=\frac{2-3 p_{i}}{p_{i}}$ & $\mathrm{~F}_{\mathrm{HOM}}=1$ & $\mathrm{~F}_{\mathrm{UNI}}=\frac{1-p_{i}}{p_{i}}$ \\
\hline$x_{i}$ is the number
\end{tabular}

\section{Results}

We used five different approaches $\left(\mathrm{F}_{\mathrm{PED}}, \mathrm{F}_{\mathrm{GRM}}, \mathrm{F}_{\mathrm{HOM}}\right.$, $\left.\mathrm{F}_{\mathrm{UNI}}, \mathrm{F}_{\mathrm{ROH}}\right)$ to estimate inbreeding coefficients using information from three different sources: pedigree, whole genome sequence and 50k SNP chip genotype data. There were total 11 estimates of inbreeding coefficients for each animal (Table 2). The average inbreeding coefficients estimated using different approaches and different data sets are presented in Table 2. The $F_{P E D}$ and $F_{R O H}$ estimated from $50 \mathrm{k}$ data for $\mathrm{HOL}$ and JER are significantly higher than for RDC $(p<0.05)$. For inbreeding coefficients estimated from sequence data, $F_{\mathrm{ROH}}, \mathrm{F}_{\mathrm{ROH}>1 \mathrm{Mb}}, \mathrm{F}_{\mathrm{ROH}>3 \mathrm{Mb}}$, $\mathrm{F}_{\mathrm{HOM}}$ and $\mathrm{F}_{\mathrm{UNI}}$ differed significantly among breeds, being highest in JER and lowest in RDC. The mean $\mathrm{F}_{\mathrm{ROH}}$ for $50 \mathrm{k}$ SNP chip data (0.066), and sequence data (0.19) are significantly higher than $\mathrm{F}_{\mathrm{PED}}(0.016)(p<0.01)$.

$\mathrm{F}_{\mathrm{ROH}}$ estimated from sequence data is a direct and accurate estimate of the levels of homozygosity. It mostly reflects regions which were IBD on the genome; therefore, we limited our comparisons to comparing between $\mathrm{F}_{\mathrm{ROH}}$ from sequence data with other estimates of F. High correlations were observed between $\mathrm{F}_{\mathrm{ROH}}$ estimated from the $50 \mathrm{k}$ and sequence data with $\mathrm{F}_{\mathrm{ROH}>1 \mathrm{Mb}}$ and
$\mathrm{F}_{\mathrm{ROH}>3 \mathrm{Mb}}$ from the sequence data for all three breeds (Tables 3, 4 and 5). The correlation between $\mathrm{F}_{\mathrm{ROH}}$ estimated from $50 \mathrm{k}$ data and $\mathrm{F}_{\mathrm{ROH}>3 \mathrm{Mb}}$ was higher than $\mathrm{F}_{\mathrm{ROH}}$ estimated from $50 \mathrm{k}$ data and $\mathrm{F}_{\mathrm{ROH}>1 \mathrm{Mb}}$ in JER and RDC (Tables 4 and 5). $\mathrm{F}_{\mathrm{ROH}}$ was consistently positively correlated with $\mathrm{F}_{\mathrm{HOM}}$ and $\mathrm{F}_{\mathrm{UNI}}$, when both were computed from either $50 \mathrm{k}$ or sequence data in all three breeds (Tables 3, 4 and 5). A high correlation was found between $\mathrm{F}_{\mathrm{ROH}}$ and $\mathrm{F}_{\mathrm{UNI}}$, when both were computed from either $50 \mathrm{k}$ or sequence data in all three breeds (Tables 3, 4 and 5). However, for different breeds, $\mathrm{F}_{\mathrm{HOM}}$ and $\mathrm{F}_{\mathrm{UNI}}$ were correlated differently across different densities of genomic data. For HOL and RDC, the higher the density of genomic data used for $\mathrm{F}_{\mathrm{UNI}}$, the higher the correlation was between $\mathrm{F}_{\mathrm{UNI}}$ and $\mathrm{F}_{\mathrm{ROH}}$ from sequence data (Tables 3 and 5). For $\mathrm{HOL}$, the correlation between $\mathrm{F}_{\mathrm{UNI}}$ and $\mathrm{F}_{\mathrm{ROH}}$ from sequence data (0.95) was still higher than the correlation between $\mathrm{F}_{\mathrm{ROH}}$ estimated from 50k SNP chip data and sequence data (0.87) (Table 3). In contrast to JER, $\mathrm{F}_{\mathrm{HOM}}$ and $\mathrm{F}_{\mathrm{UNI}}$ were most highly correlated with $\mathrm{F}_{\mathrm{ROH}}$ estimated from sequence data (Table 5).

$F_{\text {PED }}$ was mostly intermediately correlated with $\mathrm{F}_{\mathrm{HOM}}$ and $\mathrm{F}_{\mathrm{ROH}}$ estimated from $50 \mathrm{k}$ and sequence data. The highest correlation between $F_{P E D}$ and $F_{R O H}$ estimated from $50 \mathrm{k}$ and sequence data was found in HOL (Table 3). The strongest correlation among estimators of $\mathrm{F}_{\mathrm{ROH}}\left(\mathrm{F}_{\mathrm{ROH}}\right.$ from $50 \mathrm{k}$ or sequence data or $\mathrm{F}_{\mathrm{ROH}>3 \mathrm{Mb}}$ or $\mathrm{F}_{\mathrm{ROH}>1 \mathrm{Mb}}$ from sequence data) and $\mathrm{F}_{\mathrm{PED}}$ was observed between $F_{P E D}$ and $F_{R O H}>3 M b$ from sequence data in HOL (Table 3). A moderate correlation was found between $F_{P E D}$ and $F_{R O H}$ estimated from $50 \mathrm{k}$ and sequence data for JER and RDC (Tables 4 and 5).

Table 2 Estimated mean (min-max) of pedigree-based inbreeding coefficient ( $\left.F_{P E D}\right)$, GRM-based inbreeding coefficient ( $\left.F_{G R M}\right)$, inbreeding coefficients based on excess of homozygosity $\left(\mathrm{F}_{\mathrm{HOM}}\right)$, inbreeding coefficients based on correlation between uniting gametes $\left(\mathrm{F}_{\mathrm{UNI}}\right)$, ROH-based inbreeding coefficients $\left(\mathrm{F}_{\mathrm{ROH}}\right)$. $\mathrm{F}_{\mathrm{ROH}}$ greater than $1 \mathrm{Mb}, 3 \mathrm{Mb}$ derived from sequence data were reported

\begin{tabular}{|c|c|c|c|c|c|c|c|}
\hline \multirow[b]{2}{*}{ Inbreeding coefficients } & & \multirow[b]{2}{*}{$\mathrm{HOL}$} & \multicolumn{2}{|l|}{ Mean } & \multirow[b]{2}{*}{$\mathrm{HOL}$} & \multicolumn{2}{|l|}{ Range } \\
\hline & & & JER & $\mathrm{RDC}$ & & JER & $\mathrm{RDC}$ \\
\hline & $\mathrm{F}_{\mathrm{PED}}$ & $0.036^{\mathrm{A}}$ & $0.018^{B}$ & $0.003^{C}$ & $0-0.100$ & $0-0.060$ & $0-0.013$ \\
\hline \multirow[t]{4}{*}{ 50k SNP chip data } & $\mathrm{F}_{\mathrm{ROH}}$ & $0.066^{\mathrm{A}}$ & $0.070^{\mathrm{A}}$ & $0.038^{\mathrm{B}}$ & $0.011-0.160$ & $0.015-0.140$ & $0.006-0.088$ \\
\hline & $F_{G R M}$ & $0.023^{A}$ & $-0.062^{\mathrm{A}}$ & $0.345^{B}$ & $-0.162-0.683$ & $-0.365-0.351$ & $-0.055-0.653$ \\
\hline & $\mathrm{F}_{\mathrm{HOM}}$ & $-0.008^{\mathrm{A}}$ & $-0.001^{\mathrm{A}}$ & $-0.234^{B}$ & $-0.420-0.185$ & $-0.227-0.147$ & $-0.403-(-0.021)$ \\
\hline & $\mathrm{F}_{\text {UNI }}$ & $0.013^{\mathrm{A}}$ & $-0.031^{B}$ & $0.057^{C}$ & $-0.076-0.274$ & $-0.121-0.063$ & $-0.048-0.177$ \\
\hline \multirow[t]{6}{*}{ Sequence data } & $\mathrm{F}_{\mathrm{ROH}}$ & $0.187^{A}$ & $0.242^{B}$ & $0.118^{C}$ & $0.087-0.271$ & $0.193-0.294$ & $0.043-0.177$ \\
\hline & $\mathrm{F}_{\mathrm{ROH}>1 \mathrm{Mb}}$ & $0.113^{\mathrm{A}}$ & $0.162^{B}$ & $0.055^{c}$ & $0.060-0.205$ & $0.104-0.225$ & $0.009-0.110$ \\
\hline & $\mathrm{F}_{\mathrm{ROH}>3 \mathrm{Mb}}$ & $0.070^{A}$ & $0.089^{B}$ & $0.027^{C}$ & $0.017-0.167$ & $0.033-0.158$ & $0-0.079$ \\
\hline & $F_{G R M}$ & $-0.108^{\mathrm{A}}$ & $-0.122^{\mathrm{A}}$ & $0.014^{B}$ & $-0.189-0.031$ & $-0.179-(-0.031)$ & $-0.244-0.34$ \\
\hline & $\mathrm{F}_{\mathrm{HOM}}$ & $0.069^{\mathrm{A}}$ & $0.145^{B}$ & $-0.123^{C}$ & $-0.082-0.208$ & $0.053-0.231$ & $-0.408-0.061$ \\
\hline & $F_{U N I}$ & $0.028^{\mathrm{A}}$ & $0.059^{B}$ & $-0.007^{C}$ & $-0.031-0.087$ & $0.024-0.108$ & $-0.054-0.055$ \\
\hline
\end{tabular}


Table 3 Correlation coefficients between different estimates for inbreeding from different data sets for HOL

\begin{tabular}{|c|c|c|c|c|c|c|c|c|c|c|c|c|}
\hline \multirow[t]{2}{*}{ Correlation } & & \multirow[t]{2}{*}{$\mathrm{F}_{\mathrm{PED}}$} & \multicolumn{4}{|c|}{ 50k SNP chip data } & \multicolumn{6}{|c|}{ Sequence data } \\
\hline & & & $\mathrm{F}_{\mathrm{ROH}}$ & $\mathrm{F}_{\mathrm{GRM}}$ & $\mathrm{F}_{\mathrm{HOM}}$ & $\mathrm{F}_{\mathrm{UNI}}$ & $\mathrm{F}_{\mathrm{ROH}}$ & $\mathrm{F}_{\mathrm{ROH}>1 \mathrm{Mb}}$ & $\mathrm{F}_{\mathrm{ROH}>3 \mathrm{Mb}}$ & $F_{G R M}$ & $\mathrm{~F}_{\mathrm{HOM}}$ & $\mathrm{F}_{\text {UNI }}$ \\
\hline$F_{P E D}$ & & 1 & $0.82^{* *}$ & -0.20 & $0.58^{* *}$ & 0.20 & $0.73^{* *}$ & $0.83^{* *}$ & $0.84^{* *}$ & -0.26 & $0.78^{* *}$ & $0.68^{* *}$ \\
\hline \multirow[t]{4}{*}{ 50k SNP chip data } & $\mathrm{F}_{\mathrm{ROH}}$ & & 1 & -0.23 & $0.61^{* *}$ & 0.15 & $0.87^{* *}$ & $0.96^{* *}$ & $0.96^{* *}$ & 0.03 & $0.70^{* *}$ & $0.88^{* *}$ \\
\hline & $F_{G R M}$ & & & 1 & $-0.83^{* *}$ & $0.87^{* *}$ & -0.10 & -0.13 & -0.16 & $0.36^{*}$ & -0.31 & -0.0005 \\
\hline & $\mathrm{F}_{\mathrm{HOM}}$ & & & & 1 & $-0.44^{*}$ & $0.50^{* *}$ & $0.58^{* *}$ & $0.67^{* *}$ & $-0.38^{*}$ & $0.66^{* *}$ & $0.41^{*}$ \\
\hline & $\mathrm{F}_{\mathrm{UNI}}$ & & & & & 1 & 0.27 & 0.29 & 0.27 & 0.21 & 0.11 & 0.35 \\
\hline \multirow[t]{6}{*}{ Sequence data } & $\mathrm{F}_{\mathrm{ROH}}$ & & & & & & 1 & $0.96^{* *}$ & $0.91^{* *}$ & 0.09 & $0.71^{* *}$ & $0.95^{* *}$ \\
\hline & $\mathrm{F}_{\mathrm{ROH}}>1 \mathrm{Mb}$ & & & & & & & 1 & $0.98^{* *}$ & 0.01 & $0.77^{* *}$ & $0.94^{* *}$ \\
\hline & $\mathrm{F}_{\mathrm{ROH}}>3 \mathrm{Mb}$ & & & & & & & & 1 & -0.32 & $0.77^{* *}$ & $0.90^{* *}$ \\
\hline & $F_{G R M}$ & & & & & & & & & 1 & $-0.61^{* *}$ & 0.29 \\
\hline & $\mathrm{F}_{\mathrm{HOM}}$ & & & & & & & & & & 1 & $0.58^{* *}$ \\
\hline & FUNI & & & & & & & & & & & 1 \\
\hline
\end{tabular}

*: significantly different from 0 at $p<0.05$; ${ }^{* *}$ : significantly different from 0 at $p<0.01 . \mathrm{F}_{\mathrm{PED}}$ is the inbreeding coefficient estimated from pedigree data. $\mathrm{F}_{\mathrm{ROH}}$ is inbreeding coefficient estimated based on $\mathrm{ROH}$ for $50 \mathrm{k}$ data and for sequence data $\mathrm{F}_{\mathrm{ROH}>1 \mathrm{Mb}}$ and $\mathrm{F}_{\mathrm{ROH}>3 \mathrm{Mb}}$ are also reported. $\mathrm{F}_{\mathrm{GRM}}$ is $\mathrm{GRM}$-based inbreeding coefficient estimated from $50 \mathrm{k}$ and sequence data. $\mathrm{F}_{\mathrm{HOM}}$ is inbreeding coefficient estimated based on excess of homozygosity for $50 \mathrm{k}$ and sequence data. $F_{\mathrm{UNI}}$ is the inbreeding coefficient estimated based on correlation of uniting gametes for $50 \mathrm{k}$ and sequence data

The estimate $\mathrm{F}_{\mathrm{GRM}}$ from both $50 \mathrm{k}$ and sequence data and $\mathrm{F}_{\mathrm{PED}}$ had a correlation close to zero in all three breeds and the values were often negative (Tables 3, 4 and 5). At the same time, $F_{G R M}$ estimated from $50 \mathrm{k}$ and sequence data generally showed a low correlation with other estimates except between two estimates $\mathrm{F}_{\mathrm{GRM}}$ estimated from $50 \mathrm{k}$ and sequence data in $\mathrm{HOL}$ and JER, and between $\mathrm{F}_{\mathrm{GRM}}$ and $\mathrm{F}_{\mathrm{UNI}}$ estimated from $50 \mathrm{k}$ data (Tables 3 and 4).

\section{Discussion}

Pedigree has been used to estimate inbreeding coefficients in animal breeding for over 50 years $[1,17]$. Recently, researchers have utilized runs of homozygosity
$(\mathrm{ROH})$ estimated from medium density genotype data such as 50k SNP chip data to estimate inbreeding coefficients in livestock populations $[22-24,30]$. $\mathrm{ROH}$ were initially used to explore regions of inbreeding in the genome and further investigate the fitness effect of these regions on different traits $[2,9,11,43]$. Population subdivision and either inbreeding or inbreeding avoidance affects the whole genome composition, whereas selection and assortative mating will affect only those loci associated with particular phenotypes. However, we observed that inbreeding coefficient $\mathrm{F}_{\mathrm{ROH}}$ estimated from sequence data were relatively higher for chromosome 1 and 10 for all four breeds (Fig. 1). This is most likely because the local recombination rate is relatively lower

Table 4 Correlation coefficients between different estimates for inbreeding from different data sets for JER

\begin{tabular}{|c|c|c|c|c|c|c|c|c|c|c|c|c|}
\hline \multirow[t]{2}{*}{ Correlation } & & \multirow[t]{2}{*}{$F_{P E D}$} & \multicolumn{4}{|c|}{ 50k SNP chip data } & \multicolumn{6}{|c|}{ Sequence data } \\
\hline & & & $\overline{\mathrm{F}_{\mathrm{ROH}}}$ & $\mathrm{F}_{\text {GRM }}$ & $\mathrm{F}_{\mathrm{HOM}}$ & $\mathrm{F}_{\mathrm{UNI}}$ & $\overline{\mathrm{F}_{\mathrm{ROH}}}$ & $\mathrm{F}_{\mathrm{ROH}>1 \mathrm{Mb}}$ & $\mathrm{F}_{\mathrm{ROH}>3 \mathrm{Mb}}$ & $\mathrm{F}_{\mathrm{GRM}}$ & $\mathrm{F}_{\mathrm{HOM}}$ & $F_{\text {UNI }}$ \\
\hline $\mathrm{F}_{\mathrm{PED}}$ & & 1 & $0.47^{*}$ & -0.18 & $0.46^{*}$ & 0.25 & $0.46^{*}$ & $0.52^{*}$ & $0.53^{*}$ & -0.21 & $0.60^{* *}$ & $0.43^{*}$ \\
\hline \multirow[t]{4}{*}{ 50k SNP chip data } & $\mathrm{F}_{\mathrm{ROH}}$ & & 1 & 0.36 & 0.06 & $0.79^{* *}$ & $0.92^{* *}$ & $0.93^{* *}$ & $0.96^{* *}$ & 0.29 & $0.67^{* *}$ & $0.96^{* *}$ \\
\hline & $F_{G R M}$ & & & 1 & $-0.89^{* *}$ & $0.80^{* *}$ & 0.19 & 0.16 & 0.22 & $0.86^{* *}$ & -0.34 & $0.44^{*}$ \\
\hline & $\mathrm{F}_{\mathrm{HOM}}$ & & & & 1 & 0.24 & 0.28 & 0.21 & $-0.76^{* *}$ & $0.66^{* *}$ & -0.01 & 0.24 \\
\hline & $\mathrm{F}_{\text {UNI }}$ & & & & & $0.67^{* *}$ & $0.67^{* *}$ & $0.71^{* *}$ & $0.69^{* *}$ & 0.20 & $0.84^{* *}$ & $0.67^{* *}$ \\
\hline \multirow[t]{6}{*}{ Sequence data } & $\mathrm{F}_{\mathrm{ROH}}$ & & & & & & 1 & $0.99^{* *}$ & $0.96^{* *}$ & 0.14 & $0.76^{* *}$ & $0.92^{* *}$ \\
\hline & $\mathrm{F}_{\mathrm{ROH}>1 \mathrm{Mb}}$ & & & & & & & 1 & $0.97^{* *}$ & 0.094 & $0.80^{* *}$ & $0.91^{* *}$ \\
\hline & $\mathrm{F}_{\mathrm{ROH}>3 \mathrm{Mb}}$ & & & & & & & & 1 & 0.20 & $0.74^{* *}$ & $0.95^{* *}$ \\
\hline & $F_{G R M}$ & & & & & & & & & 1 & $-0.48^{*}$ & $0.42^{*}$ \\
\hline & $\mathrm{F}_{\mathrm{HOM}}$ & & & & & & & & & & 1 & $0.60^{* *}$ \\
\hline & FUNI & & & & & & & & & & & 1 \\
\hline
\end{tabular}

${ }^{*}$ : significantly different from 0 at $p<0.05 ;{ }^{*}$ : significantly different from 0 at $p<0.01$. $\mathrm{F}_{\mathrm{PED}}$ is the inbreeding coefficient estimated from pedigree data. $\mathrm{F}_{\mathrm{ROH}}$ is inbreeding coefficient estimated based on $\mathrm{ROH}$ for $50 \mathrm{k}$ data and for sequence data $\mathrm{F}_{\mathrm{ROH}>1 \mathrm{Mb}}$ and $\mathrm{F}_{\mathrm{ROH}>3 \mathrm{Mb}}$ are also reported. $\mathrm{F}_{\mathrm{GRM}}$ is $\mathrm{GRM}$-based inbreeding coefficient estimated from $50 \mathrm{k}$ and sequence data. $\mathrm{F}_{\mathrm{HOM}}$ is inbreeding coefficient estimated based on excess of homozygosity for $50 \mathrm{k}$ and sequence data. $\mathrm{F}_{\mathrm{UNI}}$ is the inbreeding coefficient estimated based on correlation of uniting gametes for $50 \mathrm{k}$ and sequence data 
Table 5 Correlation coefficients between different estimates for inbreeding from different data sets for RDC

\begin{tabular}{|c|c|c|c|c|c|c|c|c|c|c|c|c|}
\hline \multirow[t]{2}{*}{ Correlation } & & \multirow[t]{2}{*}{$F_{P E D}$} & \multicolumn{4}{|c|}{ 50k SNP chip data } & \multicolumn{6}{|c|}{ Sequence data } \\
\hline & & & $\mathrm{F}_{\mathrm{ROH}}$ & $F_{G R M}$ & $\mathrm{~F}_{\mathrm{HOM}}$ & $\mathrm{F}_{\mathrm{UNI}}$ & $\mathrm{F}_{\mathrm{ROH}}$ & $\mathrm{F}_{\mathrm{ROH}>1 \mathrm{Mb}}$ & $\mathrm{F}_{\mathrm{ROH}>3 \mathrm{Mb}}$ & $F_{G R M}$ & $\mathrm{~F}_{\mathrm{HOM}}$ & $\mathrm{F}_{\text {UNI }}$ \\
\hline$F_{P E D}$ & & 1 & $0.54^{* *}$ & $0.36^{*}$ & -0.31 & $0.45^{*}$ & $0.49^{* *}$ & $0.54^{* *}$ & $0.51^{* *}$ & -0.21 & $0.37^{*}$ & 0.32 \\
\hline \multirow[t]{4}{*}{ 50k SNP chip data } & $\mathrm{F}_{\mathrm{ROH}}$ & & 1 & $0.41^{*}$ & 0.35 & $0.80^{* *}$ & $0.85^{* *}$ & $0.96^{* *}$ & $0.98^{* *}$ & 0.08 & 0.21 & $0.77^{* *}$ \\
\hline & $F_{G R M}$ & & & 1 & $-0.66^{* *}$ & $0.82^{* *}$ & 0.22 & 0.34 & $0.38^{*}$ & -0.36 & $0.43^{*}$ & 0.05 \\
\hline & $\mathrm{F}_{\mathrm{HOM}}$ & & & & 1 & -0.10 & $0.40^{*}$ & $0.40^{*}$ & $0.38^{*}$ & $0.38^{*}$ & -0.23 & 0.52 \\
\hline & $F_{U N I}$ & & & & & 1 & $0.60^{* *}$ & $0.76^{* *}$ & $0.79^{* *}$ & -0.20 & $0.40^{*}$ & $0.46^{*}$ \\
\hline \multirow[t]{6}{*}{ Sequence data } & $\mathrm{F}_{\mathrm{ROH}}$ & & & & & & 1 & $0.93^{* *}$ & $0.87^{* *}$ & 0.003 & 0.31 & $0.81^{* *}$ \\
\hline & $\mathrm{F}_{\mathrm{ROH}>1 \mathrm{Mb}}$ & & & & & & & 1 & $0.97^{* *}$ & 0.010 & 0.29 & $0.79^{* *}$ \\
\hline & $\mathrm{F}_{\mathrm{ROH}>3 \mathrm{Mb}}$ & & & & & & & & 1 & 0.038 & 0.25 & $0.76^{* *}$ \\
\hline & $F_{G R M}$ & & & & & & & & & 1 & $-0.95^{* *}$ & $0.54^{* *}$ \\
\hline & $\mathrm{F}_{\mathrm{HOM}}$ & & & & & & & & & & 1 & -0.24 \\
\hline & FUNI $_{\text {Un }}$ & & & & & & & & & & & 1 \\
\hline
\end{tabular}

*: significantly different from 0 at $p<0.05$; ${ }^{*}$ : significantly different from 0 at $p<0.01 . \mathrm{F}_{\mathrm{PED}}$ is the inbreeding coefficient estimated from pedigree data. $\mathrm{F}_{\mathrm{ROH}}$ is inbreeding coefficient estimated based on $\mathrm{ROH}$ for $50 \mathrm{k}$ data and for sequence data $\mathrm{F}_{\mathrm{ROH}>1 \mathrm{Mb}}$ and $\mathrm{F}_{\mathrm{ROH}>3 \mathrm{Mb}}$ are also reported. $\mathrm{F}_{\mathrm{GRM}}$ is $\mathrm{GRM}$-based inbreeding coefficient estimated from $50 \mathrm{k}$ and sequence data. $\mathrm{F}_{\mathrm{HOM}}$ is inbreeding coefficient estimated based on excess of homozygosity for $50 \mathrm{k}$ and sequence data. $\mathrm{F}_{\mathrm{UNI}}$ is the inbreeding coefficient estimated based on correlation of uniting gametes for 50k and sequence data

than average, which results in high levels of homozygosity on average [23, 44].

Our study is the first to calculate inbreeding coefficient based on $\mathrm{ROH}$ from full sequence data in cattle. The objective of this study was to compare estimates of inbreeding calculated from different methods and different data sources (pedigree, 50k SNP chip genotypes and full sequence data).

The pedigree-based inbreeding coefficient, $F_{\mathrm{PED}}$, was moderately correlated with $\mathrm{F}_{\mathrm{HOM}}$ and $\mathrm{F}_{\mathrm{ROH}}$ in all breeds. These moderate correlations $(\sim 0.47$ to 0.56$)$ may be partly explained by the relatively shallow depth of the

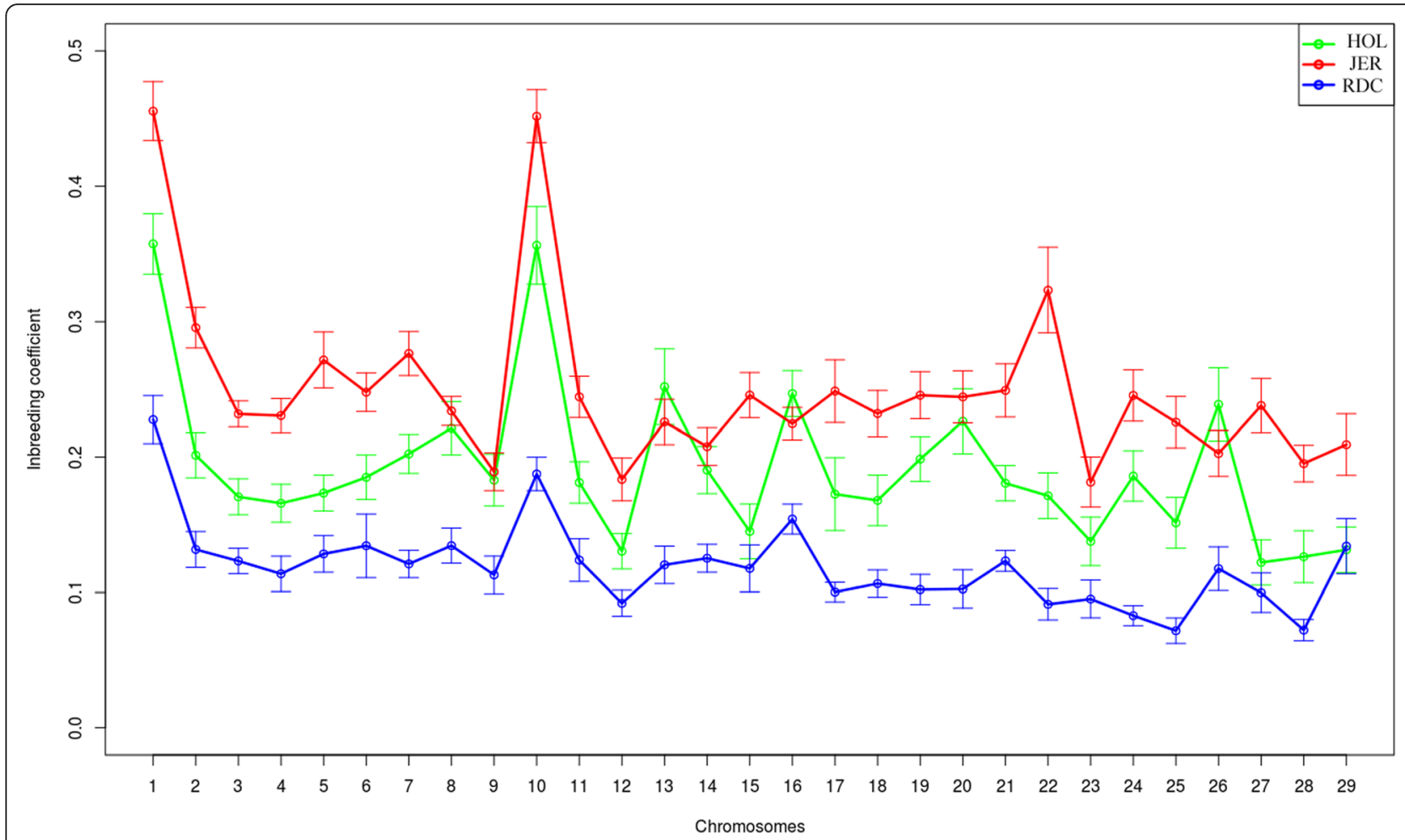

Fig. 1 Distribution of inbreeding coefficients $\mathrm{F}_{\mathrm{ROH}}$ estimated from sequence data using $\mathrm{ROH}$ for each chromosome in three breeds. Inbreeding coefficients $\mathrm{F}_{\mathrm{ROH}}$ estimated from sequence data versus chromosomes 1-29 in HOL. JER and RDC. Standard error bars were computed among individuals within $\mathrm{HOL}$, JER and RDC 
pedigree records ( 8-9) for these bulls. Another difference between $\mathrm{F}_{\mathrm{ROH}}$ and $\mathrm{F}_{\mathrm{PED}}$ is that short $\mathrm{ROH}$ capture ancient inbreeding while long $\mathrm{ROH}$ capture recent inbreeding whereas pedigree captures only relatively recent inbreeding. Pedigree accounts only for inbreeding that occurred since pedigree recording began. Therefore, after excluding $\mathrm{ROH}$ smaller than 1 or $3 \mathrm{Mbp}$, the correlation between $F_{\mathrm{PED}}$ and $\mathrm{F}_{\mathrm{ROH}}$ from sequence data increased slightly for all breeds. We should also point out that a very long stretch of homozygosity using marker data might not actually be completely homozygous and therefore, higher density data was suggested to be used to detect selective sweeps through runs of homozygosity [45]. Sørensen et al. [7] has estimated inbreeding in Danish Dairy Cattle Breeds and our estimates $F_{P E D}$ are lower than theirs. This is because our sampled animals for sequencing are founder and older animals compare to the other study where they used all animals [7].

Estimates of inbreeding coefficients differed with methods. Inbreeding coefficients estimates from methods using allele frequencies, i.e., $F_{\mathrm{GRM}}, \mathrm{F}_{\mathrm{HOM}}$ and $\mathrm{F}_{\mathrm{UNI}}$, showed considerable variation across data type and breeds. These estimators were sensitive to allele frequencies compared to $\mathrm{ROH}$ estimators, especially for populations with divergent allele frequencies (e.g., Fig. 2; RDC population).
The estimates of genomic inbreeding coefficients are dependent on the allele frequencies in the base population [40].

In order to explore the reasons about the various correlations between inbreeding coefficients estimates using allele frequencies, $F_{\mathrm{GRM}}, \mathrm{F}_{\mathrm{HOM}}$ and $\mathrm{F}_{\mathrm{UNI}}$ were plotted against the allele frequency changing from 0 to 1 when the number of copies of reference alleles for $i^{\text {th }}$ SNP is 0 , 1 or 2 (Figs. 3, 4 and 5). When a locus is homozygous for either the reference alleles or the non-reference alleles with the allele frequency ranging from 0 to $1, \mathrm{~F}_{\mathrm{GRM}}$ ranged from -1 to infinity, $\mathrm{F}_{\mathrm{HOM}}$ has a constant value of 1 and $\mathrm{F}_{\mathrm{UNI}}$ ranged from 0 to infinity (Figs. 3 and 5). $\mathrm{F}_{\mathrm{HOM}}$ gave constant estimates for homozygous genotypes, regardless of the allele frequency (Figs. 3 and 5). When the allele frequency of the non-reference alleles is smaller than 0.2 or larger than $0.8, \mathrm{~F}_{\mathrm{GRM}}$ was less than 0 (Figs. 3 and 5). When the allele frequency of the nonreference allele was between 0.2 and 0.5 or when the allele frequency of the reference allele was between 0.5 and $0.8, \mathrm{~F}_{\mathrm{GRM}}$ become positive and ranges from 0 to 1 (Figs. 3 and 5).

For a heterozygous locus with an allele frequency ranging from 0 to $1, \mathrm{~F}_{\mathrm{GRM}}$ and $\mathrm{F}_{\mathrm{HOM}}$ ranged from minus infinity to plus infinity, and $F_{\mathrm{UNI}}$ has a constant value of 0
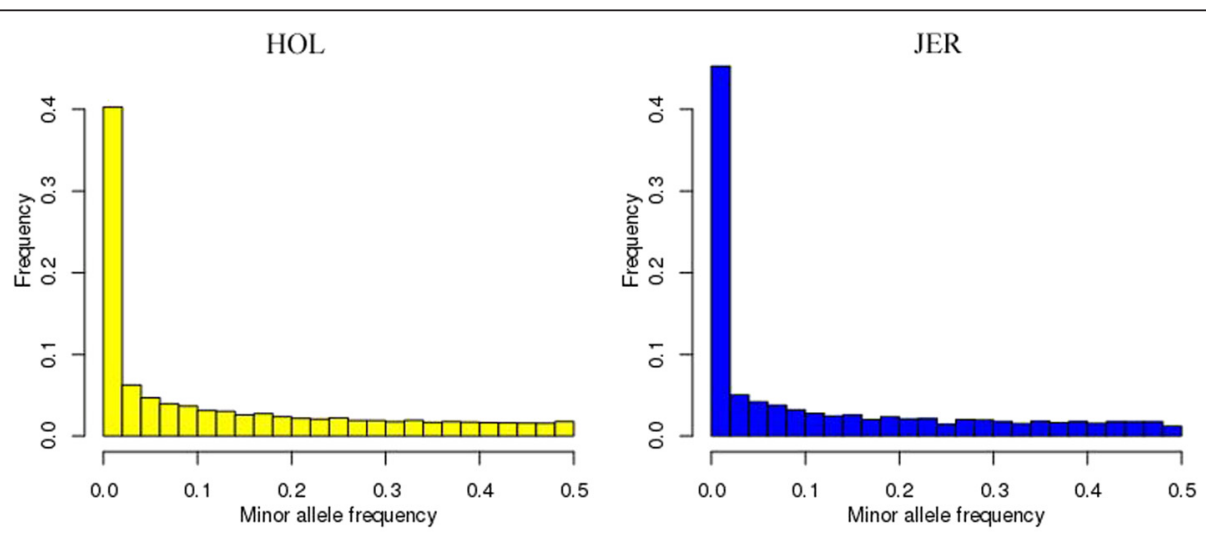

RDC

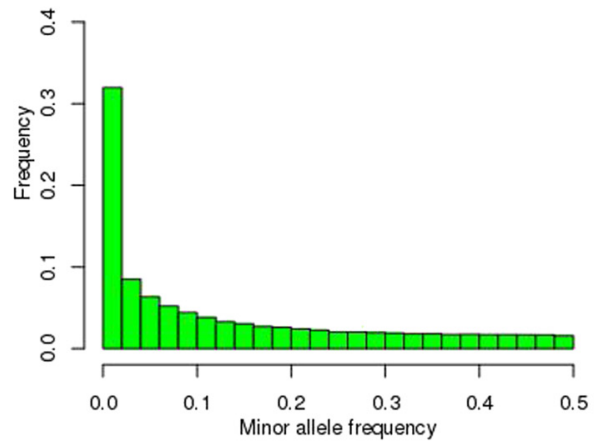

Fig. 2 Minor allele frequency distribution for HOL, JER, and RDC bulls from sequence data. Minor allele frequency in HOL (yellow), JER (blue), and $\mathrm{RDC}$ (green) bulls against the minor allele frequency among all loci 


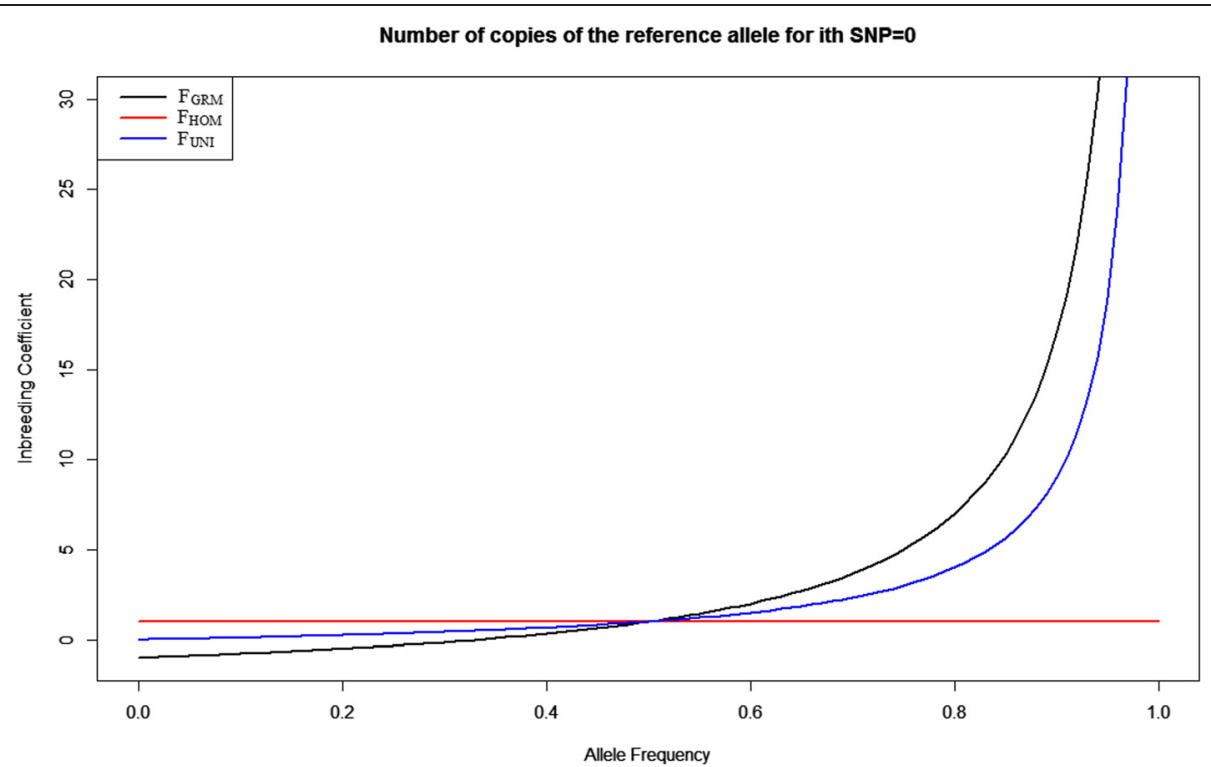

Fig. 3 Inbreeding coefficients $F_{\text {GRM }}, F_{\text {HOM }}$ and $F_{U N}$ against the reference allele frequency changing from 0 to 1 when the number of copies of reference alleles for the $i^{\text {th }}$ SNP is 0 . Black line represents $F_{G R M}$; red line represents $F_{H O M}$ and blue line represents $F_{U N I}$.

(Fig. 4). If the allele frequency was smaller than 0.2 or larger than $0.8 \mathrm{~F}_{\mathrm{GRM}}$ become very large positive whereas $\mathrm{F}_{\mathrm{HOM}}$ become a large negative. $\mathrm{F}_{\mathrm{HOM}}$ was always negative, and $\mathrm{F}_{\mathrm{GRM}}$ was always positive (Fig. 4). Thus, when a population has a high level of heterozygosity and some rare alleles with small frequency, $F_{G R M}$ would yield large positive inbreeding coefficients, which can be misleading. This result explains why $\mathrm{F}_{\mathrm{GRM}}$ was positive in the RDC breed (Table 2): this population had a higher level of heterozygosity than $\mathrm{HOL}$ and JER. $\mathrm{F}_{\mathrm{UNI}}$ gave a stable value of 0 when the locus was heterozygous and therefore was robust to allele frequency (Fig. 4).

The correlation between the three estimators $\mathrm{F}_{\mathrm{GRM}}$, $F_{\mathrm{HOM}}$ and $\mathrm{F}_{\mathrm{UNI}}$ was computed for each of the three genotypes (i.e., homozygotes for allele 1, homozygotes for allele 2 and heterozygotes) for comparison between $F_{\mathrm{GRM}}, \mathrm{F}_{\mathrm{HOM}}$ and $\mathrm{F}_{\mathrm{UNI}}$ when the allele frequency was varied between 0 and 1 (Fig. 6). Correlations reached the maximal value (i.e., 1) when the allele frequencies were 0.5 . When the allele

Number of copies of the reference allele for ith SNP=1

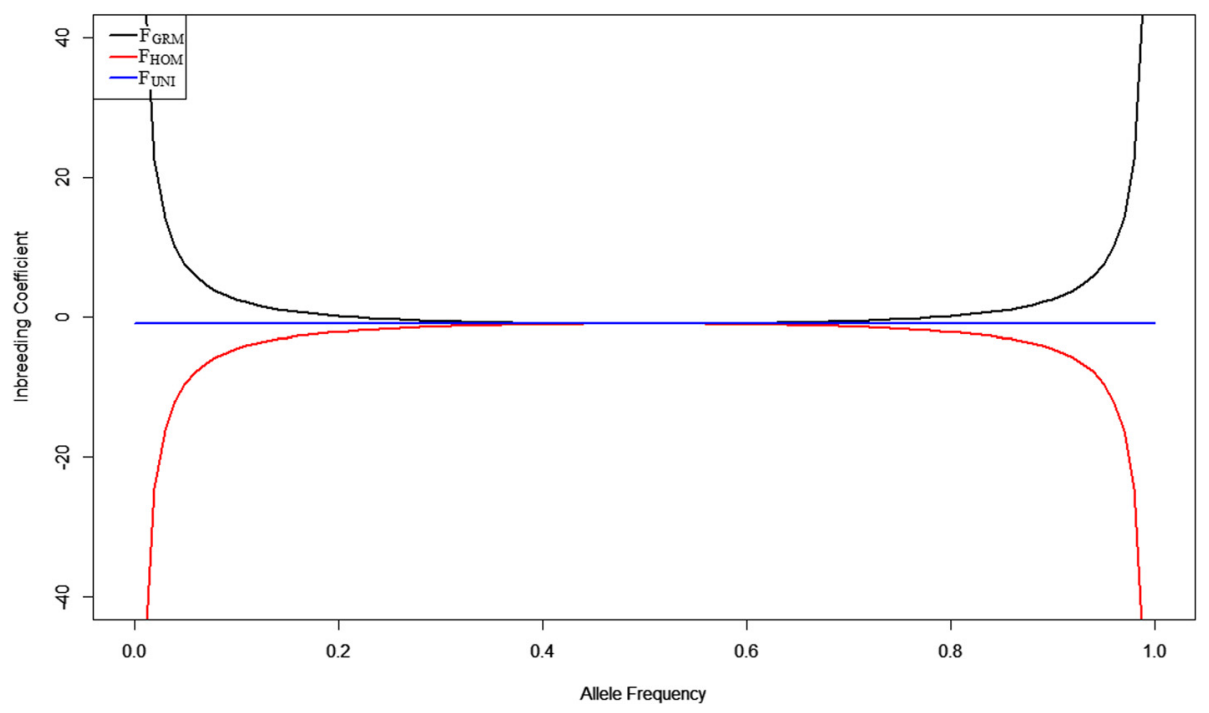

Fig. 4 Inbreeding coefficients $F_{G R M}, F_{\text {HOM }}$ and $F_{U N I}$ against the reference allele frequency changing from 0 to 1 when the number of copies of reference alleles for the $i^{\text {th }} S N P$ is 1 . Black line represents $F_{\text {GRM }}$; red line represents $F_{\text {HOM }}$ and blue line represents $F_{U N I}$ 


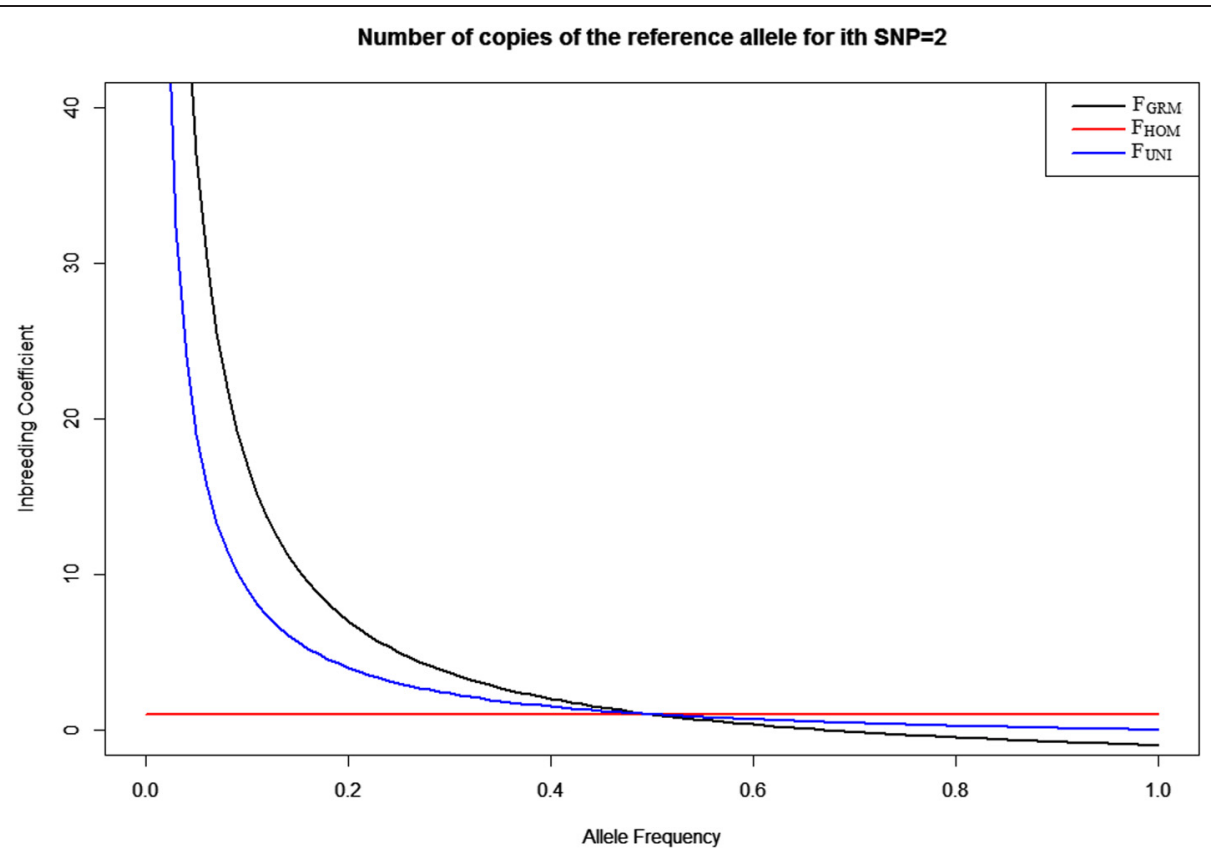

Fig. 5 Inbreeding coefficients $F_{G R M}, F_{\text {HOM }}$ and $F_{U N I}$ against the reference allele frequency changing from 0 to 1 when the number of copies of reference alleles for the $i^{\text {th }}$ SNP is 2 . Black line represents $F_{\text {GRM }}$; red line represents $F_{\text {HOM }}$ and blue line represents $F_{U N I}$

frequencies were extremely high or low, correlations between estimators became low, especially the correlation between $F_{G R M}$ and $F_{H O M}(0.27)$. The correlation plot (Fig. 6) reflected a similar result as those in Figs. 3, 4 and 5. Therefore, when computing inbreeding coefficients using allele frequencies, populations with different allele frequencies might have very different inbreeding coefficients and the correlations between those inbreeding coefficients might be very low, with different allele frequencies.

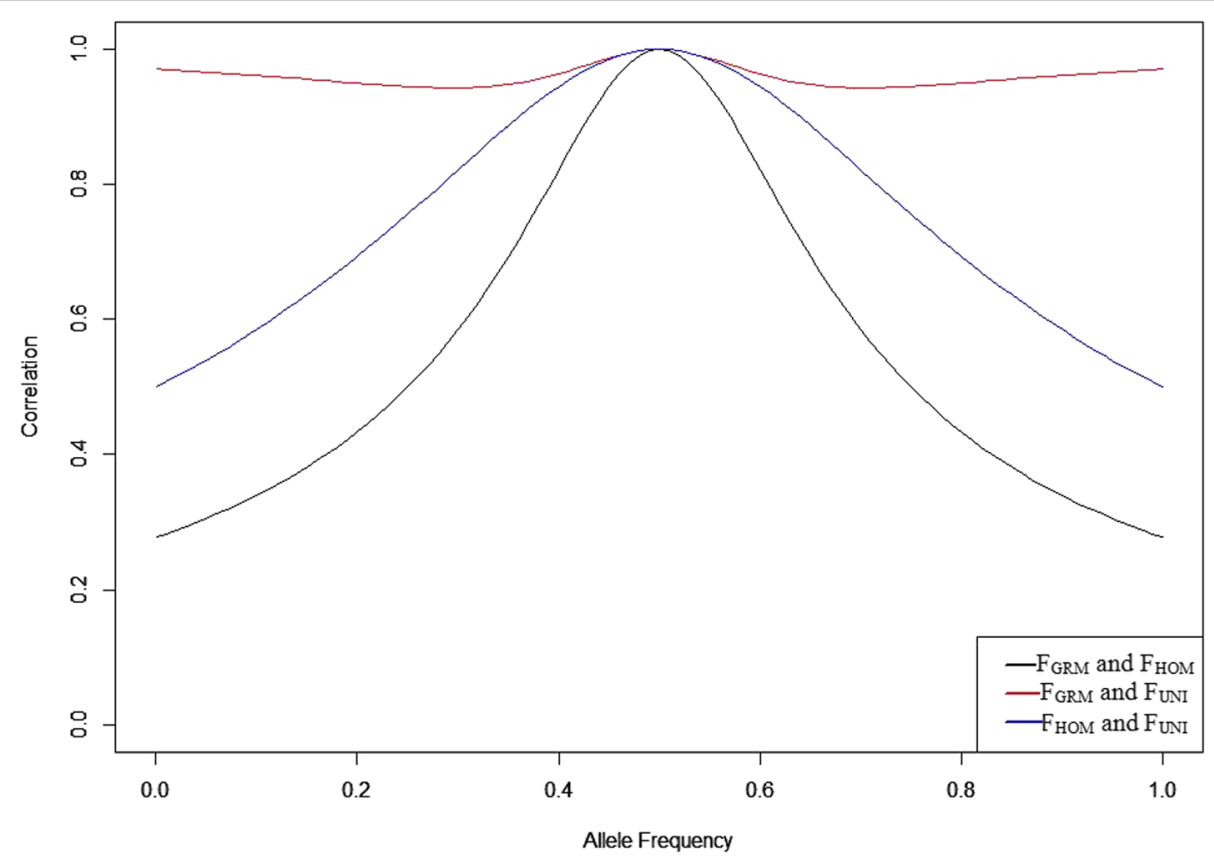

Fig. 6 Correlations between $F_{G R M}$ and $F_{H O M}, F_{G R M}$ and $F_{U N}$, and $F_{H O M}$ and $F_{U N I}$ when reference allele frequency changes between 0 and 1. Black line represents correlation between $F_{\text {GRM }}$ and $F_{\text {HOM }}$ against reference allele frequencies; red line represents correlation between $F_{G R M}$ and $F_{U N}$ against reference allele frequencies and blue line represents correlation between $F_{\text {HOM }}$ and $F_{U N I}$ against reference allele frequencies 
The comparison between $\mathrm{F}_{\mathrm{GRM}}$ and other estimators showed a very low correlation and $\mathrm{F}_{\mathrm{GRM}}$ was mostly negatively correlated with other estimators. $\mathrm{F}_{\mathrm{HOM}}$ based on excess of homozygosity was positively correlated with other estimators and was relatively highly correlated with $\mathrm{F}_{\mathrm{ROH}}$ detected from $50 \mathrm{k}$ and sequence data. $\mathrm{F}_{\mathrm{UNI}}$ based on correlations between uniting gametes estimated from $50 \mathrm{k}$ data generally was negatively correlated with other estimators. However, with increasing marker density, the correlation between $\mathrm{F}_{\mathrm{UNI}}$ and other estimators became positive for the HOL and RDC populations. Surprisingly, when using sequence data, $\mathrm{F}_{\mathrm{UNI}}$ was highly correlated with other estimators, especially $\mathrm{F}_{\mathrm{ROH}}$, detected from sequence data $(\sim 0.95)$ for HOL. This correlation may have resulted from the nature of the estimators: $\mathrm{F}_{\mathrm{ROH}}$ uses only runs of homozygosity, whereas the other estimators (to some extent) capture all of the homozygosity. This high correlation for $\mathrm{F}_{\mathrm{UNI}}$ and $\mathrm{F}_{\mathrm{ROH}}$ compared with low correlation between $\mathrm{F}_{\mathrm{GRM}}$ and $\mathrm{F}_{\mathrm{ROH}}$ might also be explained by the algorithms: $\mathrm{F}_{\mathrm{GRM}}=(1+\mathrm{F})-1$ and $\mathrm{F}$ is the correlation between uniting gametes. This estimator has only sampling on the F-term, whereas in the $F_{G R M}$ estimator there is also sampling variance on the "1", which creates additional sampling variance.

It is known that RDC is an admixed breed with introgressed haplotypes from Old Danish Red, Holstein and Brown Swiss breeds. HOL and JER are relatively pure breeds and more inbred than RDC (Zhang Q, Guldbrandtsen B, Bosse M, Lund MS, Sahana G. Runs of homozygosity and distribution of functional variants in the cattle genome. BMC Genomics (in press)). Therefore, minor allele frequencies tend to be lower in $\mathrm{HOL}$ and JER breeds than in RDC. $\mathrm{F}_{\mathrm{GRM}}$ is negatively correlated with other estimators for all three breeds. $\mathrm{F}_{\mathrm{HOM}}$ becomes negative for RDC, which is likely due to the admixture present in RDC. Therefore, it appears that $\mathrm{F}_{\mathrm{GRM}}$ tends to be less accurate for populations with a low minor allele frequency and that $\mathrm{F}_{\mathrm{HOM}}$ tends to be less accurate for populations with a higher level of heterozygosity. This argument is supported by our results that the three inbreeding estimators $\mathrm{F}_{\mathrm{GRM}}, \mathrm{F}_{\mathrm{HOM}}$ and $\mathrm{F}_{\mathrm{UNI}}$ were most closely correlated with each other when the allele frequency is approximately 0.5 (Figs. 3, 4 and 5). Therefore, the three estimators $\mathrm{F}_{\mathrm{GRM}}, \mathrm{F}_{\mathrm{HOM}}$ and $\mathrm{F}_{\mathrm{UNI}}$ depend strongly on the estimation of allele frequencies in the population, unlike $\mathrm{F}_{\mathrm{ROH}}$. However, here we only took one locus as an example to study the impact of allele frequencies on three estimators $\mathrm{F}_{\mathrm{GRM}}, \mathrm{F}_{\mathrm{HOM}}$ and $\mathrm{F}_{\mathrm{UNI}}$.

\section{Conclusion}

In this study, we compared different estimators of inbreeding coefficient with different types of data (pedigree, 50k SNP chip genotypes and full sequence data). Methods based on GRM, excess of homozygosity and the correlation between uniting gametes were observed to be sensitive to allele frequencies in the base population. The estimator based on pedigree data was moderately correlated with estimators based on $\mathrm{ROH}$ when a pedigree is relatively complete. Estimators based on ROH from SNP chip genotypes and full sequence directly reflect homozygosity on the genome, and have the advantage of not being affected by estimates of allele frequency or incompleteness of the pedigree. Inbreeding estimated from $\mathrm{ROH}$ was shown to be affected by the marker density used. Using sequence data, we obtained a full picture of the distribution of $\mathrm{ROH}$ on the genome, including short and medium length $\mathrm{ROH}$ that reflect ancient inbreeding regions which are possibly IBD. Detecting ROH based on high-density or 50k chip data was shown to give estimates most closely related to $\mathrm{ROH}$ from sequence data. However, more than $50 \mathrm{k}$ genotypes are required to accurately detect short $\mathrm{ROH}$ that are most likely identical by descent (IBD).

\section{Availability of supporting data}

Data used in this study are from the 1000 Bull Genome Project (Daetwyler et al. 2014 Nature Genet. 46:858-865). Whole genome sequence data of individual bulls of the 1000 Bull Genomes Project are already available at NCBI using SRA no. SRP039339 (http://www.ncbi.nlm.nih.gov/ bioproject/PRJNA238491).

\section{Abbreviations \\ F: Inbreeding coefficient; FPED: Pedigree based inbreeding coefficient; $\mathrm{ROH}$ : Run of homozygosity; $\mathrm{F}_{\mathrm{ROH}}$ : Runs of homozygosity-based inbreeding coefficients; GRM: Genomic relationship matrix; $F_{G R M}$ : Genomic relationship matrix-based inbreeding coefficients; $F_{\text {HOM }}$ : Inbreeding coefficients based on excess of homozygosity; $F_{U N}$ : Inbreeding coefficients based on correlation of uniting gametes; IBD: Identity by descent; SNP: Single nucleotide polymorphism; NGS: Next-generation sequence; HOL: Holstein; JER: Jersey; RDC: Danish Red Cattle; WGS: Whole-genome sequence.}

\section{Competing interests}

The authors declare that they have no competing interests.

\section{Authors' contributions}

QZ developed and planned the study design, coordinated the study, recruited the participants, performed data analyses and drafted the manuscript. MC participated in the study design, analyses of data, and drafting the manuscript. BG participated in the study design, analyses of data, and drafting the manuscript. MSL participated in study design and drafting the manuscript. GS participated in the study design, analyses of data, and drafting the manuscript. All authors read and approved the final manuscript.

\section{Acknowledgement}

Q. Zhang benefited from a joint grant from the European Commission within the framework of the Erasmus-Mundus joint doctorate "EGS-ABG". This research was supported by the Center for Genomic Selection in Animals and Plants (GenSAP) funded by The Danish Council for Strategic Research.

\section{Author details}

${ }^{1}$ Department of Molecular Biology and Genetics, Center for Quantitative Genetics and Genomics, Aarhus University, Tjele DK-8830, Denmark. ${ }^{2}$ Animal Breeding and Genomics Centre, Wageningen UR Livestock Research, Wageningen $6700 \mathrm{AH}$, The Netherlands. 
Received: 8 February 2015 Accepted: 10 June 2015

Published online: 22 July 2015

\section{References}

1. Wright S. Coefficients of inbreeding and relationship. Am Nat. 1922;56:330-8.

2. Gonzalez-Recio O, de Maturana EL, Gutierrez JP. Inbreeding depression on female fertility and calving ease in Spanish dairy cattle. J Dairy Sci. 2007;90(12):5744-52.

3. Margolin S, Bartlett JW. The influence of inbreeding upon the weight and size of dairy cattle. J Anim Sci. 1945:4(1):3-12.

4. Miglior F, Szkotnicki B, Burnside EB. Analysis of levels of inbreeding and inbreeding depression in Jersey cattle. J Dairy Sci. 1992;75(4):1112-8.

5. Nomura T, Honda T, Mukai F. Inbreeding and effective population size of Japanese black cattle. J Anim Sci. 2001;79(2):366-70.

6. Smith LA, Cassell BG, Pearson RE. The effects of inbreeding on the lifetime performance of dairy cattle. J Dairy Sci. 1998;81(10):2729-37.

7. Sorensen AC, Sorensen MK, Berg P. Inbreeding in Danish dairy cattle breeds. J Dairy Sci. 2005;88(5):1865-72.

8. Szpiech ZA, Xu JS, Pemberton TJ, Peng WP, Zollner S, Rosenberg NA, et al. Long runs of homozygosity are enriched for deleterious variation. Am J Hum Genet. 2013;93(1):90-102.

9. Bjelland DW, Weigel KA, Vukasinovic N, Nkrumah JD. Evaluation of inbreeding depression in Holstein cattle using whole-genome SNP markers and alternative measures of genomic inbreeding. J Dairy Sci. 2013;96(7):4697-706.

10. Leroy G. Inbreeding depression in livestock species: review and meta-analysis. Anim Genet. 2014;45(5):618-28.

11. Charlesworth D, Charlesworth B. Inbreeding depression and its evolutionary consequences. Annu Rev Ecol Syst. 1987;18:237-68.

12. Wright S. Systems of mating. II. The effects of inbreeding on the genetic composition of a population. Genetics. 1921;6(2):124-43.

13. Pusey A, Wolf M. Inbreeding avoidance in animals. Trends Ecol Evol. 1996;11(5):201-6.

14. Weigel K. Controlling inbreeding in modern dairy breeding programs. Adv Dairy Technol. 2006;18:263-74.

15. Mc Parland S, Kearney JF, Rath M, Berry DP. Inbreeding trends and pedigree analysis of Irish dairy and beef cattle populations. J Anim Sci. 2007:85(2):322-31.

16. Blackwell BF, Doerr PD, Reed JM, Walter JR. Inbreeding rate and effective population-size - a comparison of estimates from pedigree analysis and a demographic-model (Vol 71, Pg 299, 1995). Biol Conserv. 1995;72(3):407.

17. Meuwissen THE, Luo Z. Computing inbreeding coefficients in large populations. Genet Sel Evol. 1992;24(4):305-13.

18. Cassell BG, Adamec V, Pearson RE. Effect of incomplete pedigrees on estimates of inbreeding and inbreeding depression for days to first service and summit milk yield in Holsteins and Jerseys. J Dairy Sci. 2003;86(9):2967-76.

19. Vanraden PM. Accounting for inbreeding and crossbreeding in genetic evaluation of large populations. J Dairy Sci. 1992;75(11):3136-44.

20. McQuillan R, Leutenegger AL, Abdel-Rahman R, Franklin CS, Pericic M, Barac-Lauc $L$, et al. Runs of homozygosity in European populations. Am J Hum Genet. 2008:83(3):359-72.

21. Broman KW, Weber JL. Long homozygous chromosomal segments in reference families from the Centre d'Etude du polymorphisme humain. Am J Hum Genet. 1999;65(6):1493-500.

22. Marras G, Gaspa G, Sorbolini S, Dimauro C, Ajmone-Marsan P, Valentini A et al: Analysis of runs of homozygosity and their relationship with inbreeding in five cattle breeds farmed in Italy. Anim Genet. 2015;46(2):110-121.

23. Bosse M, Megens HJ, Madsen O, Paudel Y, Frantz LA, Schook LB, et al. Regions of homozygosity in the porcine genome: consequence of demography and the recombination landscape. PLoS Genet. 2012;8(11):e1003100.

24. Ferencakovic M, Solkner J, Curik I. Estimating autozygosity from highthroughput information: effects of SNP density and genotyping errors. Genet Sel Evol. 2013;45:42.

25. Keller MC, Visscher PM, Goddard ME. Quantification of inbreeding due to distant ancestors and its detection using dense single nucleotide polymorphism data (vol 189, pg 237, 2011). Genetics. 2012;190(1):283.

26. Kirin M, McQuillan R, Franklin CS, Campbell H, McKeigue PM, Wilson JF. Genomic runs of homozygosity record population history and consanguinity. Plos One. 2010;5(11):e13996.

27. Ku CS, Naidoo N, Teo SM, Pawitan Y. Regions of homozygosity and their impact on complex diseases and traits. Hum Genet. 2011;129(1):1-15.
28. Li JZ, Absher DM, Tang H, Southwick AM, Casto AM, Ramachandran S, et al. Worldwide human relationships inferred from genome-wide patterns of variation. Science. 2008;319(5866):1100-4.

29. Charlesworth B, Morgan MT, Charlesworth D. The effect of deleterious mutations on neutral molecular variation. Genetics. 1993;134(4):1289-303.

30. Ferencakovic M, Hamzic E, Gredler B, Solberg TR, Klemetsdal G, Curik I, et al. Estimates of autozygosity derived from runs of homozygosity: empirical evidence from selected cattle populations. J Anim Breed Genet. 2013;130(4):286-93.

31. Purfield DC, Berry DP, McParland S, Bradley DG. Runs of homozygosity and population history in cattle. BMC Genet. 2012;13:70

32. MacLeod IM, Larkin DM, Lewin HA, Hayes BJ, Goddard ME. Inferring demography from runs of homozygosity in whole-genome sequence, with correction for sequence errors. Mol Biol Evol. 2013;30(9):2209-23.

33. Wright S. Genetics of populations. Encyclopaedia Britannica. 1948;10:111-A-D-112.

34. Andersen B, Jensen B, Nielsen A, Christensen LG, Liboriussen T. Rød Dansk Malkerace-avlsmæssigt of kulturhistorisk belyst. Denmark: Danmarks HordbrugsForskning; 2003.

35. Ewing $B$, Hillier $L$, Wend MC, Green P. Base-calling of automated sequencer traces using phred. I. Accuracy assessment. Genome Res. 1998;8(3):175-85.

36. McKenna A, Hanna M, Banks E, Sivachenko A, Cibulskis K, Kernytsky A, et al. The genome analysis toolkit: a mapreduce framework for analyzing next-generation DNA sequencing data. Genome Res. 2010;20:1297-303.

37. Hoglund JK, Sahana G, Guldbrandtsen B, Lund MS. Validation of associations for female fertility traits in Nordic Holstein, Nordic Red and Jersey dairy cattle. BMC Genet. 2014;15:8.

38. Quaas RL. Computing the diagonal elements and inverse of a large numerator relationship matrix. Biometrics. 1976:32:949-953.

39. Strandén I, Vuori K: Relax2: pedigree analyses program. Proceedings of the 8th WCGALP. Belo Horizonte, MG, Brazil: Instituto Prociência; 2006.

40. VanRaden PM. Efficient methods to compute genomic predictions. J Dairy Sci. 2008;91(11):4414-23.

41. Yang JA, Lee SH, Goddard ME, Visscher PM. GCTA: a tool for genome-wide complex trait analysis. Am J Hum Genet. 2011;88(1):76-82.

42. Purcell S, Neale B, Todd-Brown $K$, Thomas L, Ferreira MAR, Bender D, et al. PLINK: a tool set for whole-genome association and population-based linkage analyses. Am J Hum Genet. 2007;81(3):559-75.

43. Pryce JE, Haile-Mariam M, Goddard ME, Hayes BJ. Identification of genomic regions associated with inbreeding depression in Holstein and Jersey dairy cattle. Genet Sel Evol. 2014;46(1):71.

44. Arias JA, Keehan M, Fisher P, Coppieters W, Spelman R. A high density linkage map of the bovine genome. BMC Genet. 2009;10:18

45. Ramey HR, Decker JE, McKay SD, Rolf MM, Schnabel RD, Taylor JF. Detection of selective sweeps in cattle using genome-wide SNP data. BMC Genomics. 2013;14:382.

\section{Submit your next manuscript to BioMed Central and take full advantage of:}

- Convenient online submission

- Thorough peer review

- No space constraints or color figure charges

- Immediate publication on acceptance

- Inclusion in PubMed, CAS, Scopus and Google Scholar

- Research which is freely available for redistribution 